BULLETIN Bulletin hispanique

HISPANIQUE Université Michel de Montaigne Bordeaux

118-1 | 2016

La Guerre Civile espagnole aujourd'hui (1936-2016)

\title{
El Tesoro de Sebastián de Covarrubias en el contexto de la tradición lexicográfica
}

\section{Alberto Hernando García-Cervigón}

\section{(2) OpenEdition}

1 Journals

\section{Edición electrónica}

URL: http://journals.openedition.org/bulletinhispanique/4360

DOI: 10.4000/bulletinhispanique.4360

ISSN: 1775-3821

\section{Editor}

Presses universitaires de Bordeaux

\section{Edición impresa}

Fecha de publicación: 15 julio 2016

Paginación: 275-296

ISBN: 979-10-300-0058-0

ISSN: 0007-4640

\section{Referencia electrónica}

Alberto Hernando García-Cervigón, «El Tesoro de Sebastián de Covarrubias en el contexto de la tradición lexicográfica », Bulletin hispanique [En línea], 118-1 | 2016, Publicado el 15 julio 2019,

consultado el 07 septiembre 2019. URL : http://journals.openedition.org/bulletinhispanique/4360 DOI : 10.4000/bulletinhispanique.4360 


\title{
El Tesoro de Sebastián de Covarrubias en el contexto de la tradición lexicográfica
}

\author{
Alberto Hernando García-Cervigón \\ Universidad Rey Juan Carlos
}

Dans cet article l'auteur étudie le Trésor de Covarrubias, premier dictionnaire général monolingue d'une langue vulgaire en Espagne et en Europe, dans le contexte de la tradition lexicographique. Il rend compte de son influence sur la lexicographie multilingue du XVII e siècle et sur le Dictionnaire des Autorités de l'Académie Royale Espagnole au XVIII ${ }^{\mathrm{e}}$ siècle.

Mots-clés: Trésor, Covarrubias, dictionnaire général monolingue, tradition lexicographique, Académie Royale Espagnole.

En este trabajo el autor estudia el Tesoro de Covarrubias, primer diccionario general monolingüe de un idioma vulgar en Espańa y Europa, en el contexto de la tradición lexicográfica, y posteriormente da cuenta de su influencia en la lexicografía plurilingüe del siglo XVII y en el Diccionario de Autoridades de la Real Academia Espańola en el siglo XVIII.

Palabras claves: Tesoro, Covarrubias, diccionario general monolingüe, tradición lexicográfica, Real Academia Española.

In this work, the author studies Covarrubias' "Thesaurus", the first monolingual general dictionary in a common language in Spain and Europe, in the context of the lexicographical tradition. He then gives an account of its influence on the multilingual lexicography of the seventeen century and on the Royal Spanish Academy's Dictionary of Authorities in the eighteen century.

Keywords: Thesaurus, Covarrubias, monolingual general dictionary, lexicographical tradition, Royal Spanish Academy. 


\section{INTRODUCCIÓN}

El propósito de Covarrubias al componer su Tesoro de la lengua castellana o española $(1611)^{1}$, el primer diccionario general monolingüe del castellano ${ }^{2}$, a la vez que el primero de este tipo publicado en Europa para una lengua vulgar, recogido en la epístola al rey Felipe III, es afrontar la ardua tarea de elaborar un diccionario etimológico de nuestra lengua en la línea de las Etimologiae de San Isidoro:

La buena memoria de Filipo Segundo, padre de V. M., hizo gran diligencia para que las obras del glorioso San Isidoro, Doctor de las Españas, se corrigiessen y emendassen por diuersos originales y de nueuo se imprimiessen con mucha curiosidad, porque gozássemos de su singular y santa dotrina y particularmente de sus Etimologías Latinas, sin embargo de que antes de el santo Doctor auían otros tratado el mesmo argumento, y después de él muchos modernos. Sospecho yo que, si alcançara Su Magestad, que santa gloria aya, ser cosa possible colegir las de su propia lengua Castellana, que no con menos cuydado lo apeteciera y procurara executar; pero hasta agora ninguno se ha atreuido a esta empressa; y los que lo han intentado, vencidos de vn trabajo inmenso, han desistido della, por la mezcla de tantas lenguas, de las quales consta la nuestra. Yo, con el desseo que he tenido y tengo de seruir a V. M., he porfiado en este intento, hasta que Dios ha sido seruido llegasse a verle el fin al cabo de muchos trabajos, de los quales la obra dará testimonio, a costa de mi salud y sosiego ${ }^{3}$.

El autor corrobora esta idea en el prólogo Al letor. Baltasar Sebastián Navarro de Arroyta, en la Carta al autor, se refiere al libro como «esta obra de las Etymologias» ${ }^{4}$. Los versos latinos del canónigo de la catedral de Cuenca Pedro de Frías van dirigidos «in librum de Hispanae linguae Etymologiis»" . En el contrato entre Covarrubias y el impresor Luis Sánchez (16 de agosto de 1610), el escribano designa el libro como «Etimoloxías, digo, Thesoro de la lengua castellana ${ }^{6}$.

1. Tesoro de la Lengua Castellana o Española. Compuesto por el Licenciado Don Sebastián de Cobarrunias Orozco, Capellán de su Magestad, Maestrescuela y Canónigo de la santa Yglesia de Cuenca, y Consultor del santo Oficio de la Inquisición. Dirigido a la Magestad Católica del Rey Don Felipe III, nuestro señor. Con privilegio. En Madrid, por Luis Sánchez, impressor del Rey N. S. Año del Señor M.DC.XI.

2. Como advierte Manuel Alvar Ezquerra, «el primer diccionario monolingüe general del español que se publica es el Tesoro de la lengua castellana o española de Sebastián de Covarrubias, si bien no es el primero en hacerlo exclusivamente en español, pues antes habían surgido bastantes repertorios especializados (náuticos, médicos, etc.) y glosarios para acompañar ciertas obras, todos ellos de extensión reducida, motivo por el que su interés para la lexicografía en general es relativa, aunque no carezcan de interés, y mucho, por otros motivos, entre ellos el lexicológico» («El Tesoro de Sebastián de Covarrubias, primer diccionario monolingüe del español», Académica. Boletín de la Real Academia Conquense de Artes y Letras, 6 [2011], p. 32).

3. Tesoro, 1611, fol. $\mathrm{H} \mathrm{r}$.

4. Tesoro, 1611, fol. D v.

5. Tesoro, 1611, fol. G r.

6. Cristóbal Pérez Pastor, Bibliografía madrileña, II, Madrid, Tipografía de la «Revista de 
Covarrubias corona de esta manera una tradición de etimologistas del español iniciada con la "Breue declaración de las sentencias y vocablos obscuros» puesta como apéndice de la Agonía del tránsito de muerte (1565), de Alejo Venegas; y seguida por las Etimologías españolas (1580), atribuidas al Brocense ${ }^{7}$; la Recopilación de algunos nombres arábigos (1593), de Diego de Guadix; el Tractado de Etymologías de voces castellanas (1600), de Bartolomé Valverde; el Origen y etymología de todos los vocablos originales de la lengua castellana (1601), de Francisco del Rosal; y Del origen y principio de la lengua castellana (1606), de Bernardo de Aldrete.

El lexicógrafo toledano conocía el libro de Aldrete $^{8}$. Es probable que su aparición fuera uno de los estímulos que lo impulsaran a componer su obra. En opinión de Martín de Riquer" ${ }^{9}$, el año en que se publica el libro de Aldrete (1606) es cuando Covarrubias comenzó la redacción del Tesoro, con la intención de superar a este autor y a todos sus predecesores. De todos modos, hay que tener en cuenta que el mismo Covarrubias declaraba hacia 1609 al redactar sus Emblemas morales haber invertido muchos años en la elaboración del diccionario ${ }^{10}$.

La diferencia entre Aldrete y Covarrubias reside en que aquel señala decididamente el fundamento latino de nuestro léxico, mientras que este se alinea con la tendencia generalizada en el siglo anterior de considerar el hebreo

Archivos, Bibliotecas y Museos», 1906, p. 198.

7. Lidio Nieto Jiménez y Manuel Alvar Ezquerra explican que «de este texto se conserva una copia manuscrita en la Biblioteca de la Real Academia Española (3-A-6), donde dice que se copió, en 1792, de uno más antiguo conservado en la Biblioteca del Monasterio de El Escorial. Se trata del manuscrito K-III-8, encabezado por el Diálogo de la Lengua de Valdés, al que siguen las etimologías, y que nos sirve de punto de partida. En él, concretamente en el folio 160, a modo de portadilla, se lee: "Acrecenté de nueuo algunos vocablos y otros van sin etymologías para que los busquemos". Y el folio 161 aparece encabezado así: "Etymologías españolas F. S. Lo que va con esta señal + son del Maestro Alexo Venegas"» (Nuevo Tesoro lexicográfico del español [S. XIV1726], Madrid, Arco/Libros, 2007, p. LXXIII).

8. En el artículo dedicado a la voz cáliž ${ }^{2}$ empleada «en lenguaje vulgar y corrupto» (Tesoro, 1611 , s. v.), Covarrubias cita expresamente el libro de Bernardo de Aldrete: «De la potencia desta ciudad y su grandeza podrás ver al Doctor Bernardo Alderete, canónigo de Córdoua, en el libro que hizo del origen de la lengua Castellana, libro 1, cap. 3, \& lib. 3, cap. 8» (Tesoro, 1611, s. v.).

9. «El Tesoro de la Lengua Castellana o Española», en Sebastián de Covarrubias, Tesoro de la Lengua Castellana o Española según la impresión de 1611, con las adiciones de Benito Remigio Noydens publicadas en la de 1674. Edición preparada por Martín de Riquer, Barcelona, S. A. Horta, I. E., 1943, p. VIII.

10. En esta obra comenta Sebastián de Covarrubias que «el architecto, auiendo de hazer vna gran fábrica, abre profundas çanjas, y en el henchir de los cimientos gasta mucho tiempo y consume gran cantidad de materiales, sin que todo esto luzga ni se eche de ver hasta llegar a la flor de la tierra, que asienta su sillería que carga con seguridad la soberuia máquina de altos muros y fuertes torreones. No sucede menos al que en su imaginación, con fuerça de ingenio, fabrica alguna obra, parto del entendimiento, como yo lo he experimentado en mi Tesoro de la lengua española, en que he trabajado muchos años hasta ponerlo en estado que pudiesse salir en público» (Emblemas morales, En Madrid, por Luis Sánchez, 1610, fol. 145 v.). 
como la lengua madre universal ${ }^{11}$. Así asigna étimo hebreo incluso a voces indígenas americanas, como Araucana ${ }^{12}$ o cacique $^{13}$.

Para Covarrubias, así como para sus predecesores y algunos de sus sucesores, la etimología es cuestión de ingenio; como diría Francisco de Quevedo años más tarde, "cosa más entretenida que demostrada»" ${ }^{14}$ Su base científica en el terreno lingüístico -el conocimiento del latín, el griego y el hebreo, y la cultura humanística- no es ni muy moderna ni muy sólida para su tiempo. Lo que más valor da a la obra, a su juicio, es el hecho de constituir la colección más extensa hasta entonces de las etimologías de la lengua española ${ }^{15}$.

El título de la obra objeto de esta investigación fue decidido por el autor tras una vacilación entre los términos Etimologías, más transparente en cuanto a su

11. En el artículo de la palabra bada el canónigo de la catedral de Cuenca introduce el comentario de que no existe ninguna lengua que no haya tenido su origen en la hebrea: «animal ferocíssimo dicho por otro nombre más común Rhinoceronte. En nuestros días truxeron al Rey Felipe II, que santa gloria aya, vna Bada, que por mucho tiempo estuuo en Madrid. Tenía asserrado el cuerno, y estaua ciega, porque no hiziesse dańo. Y curauan della con mucho recato por el peligro de los que la tenían a su cargo, de los quales mató vno o dos. El nombre de Bada es impuesto de los mesmos Indios. Mas, presupuesto que no ay lengua que no aya tenido origen de la Hebrea en la confusión del edificio de la torre de Babilonia, no será fuera de camino dezir que Bada es nombre Hebreo, de Badad, solus, solitarius» (Tesoro, 1611, s. v.).

12. A propósito de Araucana, el maestro Covarrubias explica que, al tratarse de la «prouincia de la India Occidental, vale tanto como ardiente, seca, calurosa, del verbo Hebreo arau, vel harau, arescere, ficcari, cofici. Don Alonso de Arcila, cauallero del ábito de Santiago, compuso en octauas rimas la conquista desta prouincia» (Tesoro, 1611, s. v.).

13. Por lo que respecta a cacique, anota el autor que «vale tanto, en lengua Mexicana, como señor de vassallos, y entre los bárbaros aquel es señor que tiene más fuerças para sujetar a los demás. Y presupuesto que los que poblaron el mundo después del diluuio, diuidiéndose en la confusión de lenguas al fabricar la torre de Babel o Babilonia, cada nación de las que se apartaron lleuaron consigo algún rastro de la lengua primera, en la qual auían todos hablado y quedó con Heber y su familia, de donde procedieron los Hebreos; y assí, digo que este nombre cazique puede traer origen del verbo Hebreo chazach, roborare, y de allí chezech, fortitudo \& fortis» (Tesoro, 1611: s. v.).

14. Cuento de cuentos, Zaragoza, Pedro Vergés, 1626, en Prosa festiva. Edición de Alberto Sánchez, Madrid, Castalia, 1949, p. 319.

15. Desde la publicación del Tesoro de Covarrubias hasta la actualidad, en España se han publicado numerosos diccionarios etimológicos. Entre los más representativos de los siglos XVIII y XIX, en la línea del Tesoro, se encuentran el Diccionario de Autoridades (6 vols., 1726-1739), de la Real Academia Española; el Diccionario etimológico de la lengua castellana (1856), de Pedro Felipe Monlau; y el Primer diccionario general etimológico de la lengua española (5 vols., 18801883), de Roque Barcia. El estudio científico de la etimología, que comienza en Alemania con el Etymologisches Wörterbuch der romanischen Sprachen (1853), de Friedrich Diez, en nuestro país no produce sus primeros frutos hasta mediados del siglo XX, momento a partir del cual aparecen algunas obras dignas de mención, como el Diccionario crítico etimológico de la lengua castellana (4 vols., 1954-1957), de Joan Corominas (la segunda edición, realizada con la colaboración de José A. Pascual, lleva por título Diccionario crítico etimológico castellano e hispánico [6 vols., 19801991]; y del primero se publicó también una edición abreviada con el título Breve diccionario etimológico de la lengua castellana [1961]); y el Diccionario etimológico español e hispánico (1955), de Vicente García de Diego (puesto al día y aumentado por Carmen García de Diego [1985]). 
finalidad, y Tesoro, el utilizado por «los que han hecho diccionarios copiosos» ${ }^{16}$ de sus lenguas y los han llamado así.

Esta denominación, que aparece por primera vez en el Libro del Tesoro -o Libros del Tesoro-, traducción de Li Livres dou Trésor (1260-1267), de Brunetto Latini, fue empleada en la lexicografía europea, especialmente francesa, para designar diccionarios bilingües o plurilingües ponderando su riqueza, como el Dictionarium seu Latinae linguae Thesaurus (1531), de Robert Estienne; el Thesaurus linguae Graecae (1572), de Henri Estienne; el Thesaurus linguarum (1589), de Heinrich Decimator; o el Thresor de la langue françoise (1606), de Jean Nicot.

En España, antes de Covarrubias el vocablo en cuestión había sido empleado en el Thesaurus puerilis (1575), de Onofre Pou; y en el Thesaurus verborum ac phrasium (1599), de Bartolomé Bravo. Su elección definitiva, según hacen notar José Ramón Carriazo Ruiz y M. ${ }^{a}$ Jesús Mancho Duque, «confiere al diccionario de Covarrubias la originalidad de ser el único monolingüe dentro de la tradición europea que lleva el nombre de Tesoro» ${ }^{17}$.

\section{Tratamiento del teXto del Tesoro en Sus ediciones}

1. Tras haber obtenido el informe favorable del censor Pedro de Valencia el 3 de mayo de 1610 y la concesión del privilegio en nombre del rey por Jorge de Tovar tres días después, el 16 de agosto del mismo año Covarrubias firma el contrato con el impresor madrileño Luis Sánchez para hacer una tirada «de mil cuerpos de libros de las Etimoloxías, digo, Thesoro de la lengua Castellana» ${ }^{18}$. Habiéndose llevado a cabo el proceso de impresión con normalidad, el licenciado Murcia de la Llana da fe de las erratas encontradas el 19 de octubre de 1611, año de la publicación del Tesoro de la Lengua Castellana o Española en su edición prínceps ${ }^{19}$.

16. Tesoro, 1611, fol. I $\mathrm{r}$.

17. «Los comienzos de la lexicografía monolingüe», en Antonia M. ${ }^{a}$ Medina Guerra (coord.), Lexicografía española. Presentación de Germán Colón, Barcelona, Ariel, 2003, p. 222. Después de Covarrubias se encuentra la misma designación en otros diccionarios, como el Tesoro de la lengua castellana abreviado (manuscrito anónimo del siglo XVII), inspirado en el de Covarrubias; el Tesoro de la lengua castellana (comenzado en 1693 e interrumpido en la letra C), de Juan de Ayala Manrique; el Thesaurus linguarum (1626), de Juan Ángel de Sumarán; el Thesaurus utriusque linguae hispanae et latinae (1679), de Baltasar Henríquez; el Thesaurus hispano-latinus (1714), de Pedro de Salas; el Thesaurus hispano-latinus (1717), de Valeriano Requejo; el Tesoro lexicográfico (1492-1726) (1960), de Samuel Gili Gaya; el Nuevo tesoro lexicográfico de la lengua española (2000), de la Real Academia Española; el Nuevo tesoro lexicográfico del español (S. XIV1726) (2007), de Lidio Nieto Jiménez y Manuel Alvar Ezquerra; el Tesoro lexicográfico del español de Canarias (1992), de Cristóbal Corrales Zumbado, Dolores Corbella Díaz y M. a Ángeles Álvarez Martínez; el Tesoro lexicográfico del español de Puerto Rico (2005), de María Vaquero y Amparo Morales; o el Tesoro lexicográfico del español marinero anterior a 1726 (2002), de Lidio Nieto Jiménez.

18. Cristóbal Pérez Pastor, op. cit., p. 198.

19. En la portada el título completo de esta edición prínceps, como se ha podido ver 
La obra, escrita en folios de 28,56 por $20 \mathrm{~cm}$, presenta los diez primeros sin numerar (portada, prólogo al lector, privilegio, tasa, erratas, censura, carta de Navarro de Arroyta, respuesta de Covarrubias, versos laudatorios de Pedro de Frías y dedicatoria al Rey). A continuación aparece la primera numeración, que acaba en el folio 602 y comprende hasta el final de la letra Q. Sigue una nueva numeración, que finaliza en el folio 79 y abarca las letras $\mathrm{R}$ a Z. En el folio siguiente se encuentra el colofón «En Madrid, por Luis Sánchez, impressor del Rey N. S. Año del Señor M.DC.XI.». Con ello son en total 691 folios. El vocabulario está distribuido en dos columnas, de 49 líneas cada una. En algunos ejemplares figura una segunda lista de erratas ańadida por el autor a última hora.

2. El éxito editorial del Tesoro de Covarrubias no debió de ser muy grande en su tiempo ${ }^{20}$, ya que no se hizo otra edición hasta 1674 , año en que Benito Remigio Noydens lo publica de nuevo con unas Adiciones en dos partes ${ }^{21}$, incluidas a continuación de Del origen y principio de la lengua castellana de Bernardo de Aldrete, que ocupa 91 folios de 28,56 por $19,80 \mathrm{~cm}$.

La primera parte del Tesoro contiene seis folios sin numerar en la parte superior, en los que se encuentran la portada, la censura de Pedro de Valencia, la carta de Navarro de Arroyta, la respuesta de Covarrubias, la licencia del P. Luis Vázquez firmada el 2 de octubre de 1672, una lista de erratas de las que

anteriormente, es Tesoro de la Lengua Castellana o Española. Compuesto por el Licenciado Don Sebastián de Cobarrunias Orozco, Capellán de su Magestad, Maestrescuela y Canónigo de la santa Yglesia de Cuenca, y Consultor del santo Oficio de la Inquisición. Dirigido a la Magestad Católica del Rey Don Felipe III, nuestro señor. Con privilegio. En Madrid, por Luis Sánchez, impresor del Rey N. S. Año del Señor M.DC.XI.

20. Sin embargo, desde el momento de su aparición no fue desconocido, tanto por la relevancia de su autor como por la calidad de sus contenidos. Lope de Vega le dedicó elogios en su novela Guzmán el Bravo (1624). Aparece citado por su aspecto enciclopédico en obras como los Commentaria in titulum de aleatoribus digestis et códice (1625), de Pedro Pantoja de Ayala. Bartolomé Jiménez Patón, tres años después de ver la luz, le dedicó sus Instituciones de la gramática española, como muestra de admiración y reconocimiento por su trabajo: «Al Tesoro de la Lengua Española, minas de propiedad, Indias de su elegancia, dedico, ofrezco, y enuío el ardite, plomo, y poco açogue que con mi pequeña industria e podido adquirir en estas Instituciones, reglas y precetos de su Gramática» (Instituciones de la gramática española, Baeza, Pedro de la Cuesta, 1614, fol. 2 r.).

21. El título del primer volumen es Parte primera del Tesoro de la Lengua Castellana o Española. Compuesto por el Licenciado Don Sebastián de Covarrubias Orozco, Capellán de su Magestad, Maestre-Escuela y Canónigo de la Santa Iglesia de Cuenca, y Consultor del Santo Oficio de la Inquisición. Añadido por el Padre Benito Remigio Noydens, Religioso de la Sagrada Religión de los Padres Clérigos Regulares Menores. Al Señor Don Iván de Andicano, Cauallero del Orden de Santiago, de los Consejos Supremos de su Magestad de Castilla y Guerra. Con privilegio. En Madrid, por Melchor Sánchez. A costa de Gabriel de León, Mercader de Libros. Véndese en su casa en la Puerta del Sol, 1674. Y el del segundo, Parte segunda del Tesoro de la Lengua Castellana o Española. Compuesto por el Licenciado Don Sebastián de Covarruvias Orozco, Capellán de su Magestad, Maestrescuela y Canónigo de la Santa Iglesia de Cuenca, y Consultor del Santo Oficio de la Inquisición, añadido por el Padre Benito Remigio, de los Clérigos Menores. Con privilegio. En Madrid, por Melchor Sánchez. A costa de Gabriel de León, Mercader de Libros. Véndese enfrente de la calle de la Paz, año 1673. 
da fe el licenciado Francisco Forero de Torres el 6 de marzo de 1674, la tasa fechada el 7 de marzo de 1674, el privilegio de la Reina Gobernadora otorgado el 6 de julio de 1672 y el prólogo al lector de Covarrubias. El texto de la obra alcanza hasta el folio 274 v., desde la letra A hasta el final de la E. En el folio 275 está el Elenco de las materias que se añaden en esta primera parte.

La segunda parte consta de 213 folios, desde la letra $\mathrm{F}$ hasta la Z, más otros dos sin numerar, en los que figura el elenco de las adiciones correspondientes a dichas letras. Al final, el P. Noydens hace la siguiente advertencia: «Algunos dirán que faltan muchas palabras; yo les digo que acudan al Calepino y Vocabulario, que dan bastante luz de sus significaciones. Lo que a mí me ha parecido faltar en este Tesoro (como el mismo Autor en muchas partes lo confiessa) fue el tiempo y la salud, remitiéndonos para el cumplimiento de muchas noticias a Plinio, Pierio, Dioscórides y Hortelio, \&c. Y assí para escusarte esse trabajo he procurado añadirlas, entretexiendo varias flores de Historias, Hieroglíficos y Moralidades que siruan al que las leyere de enseñança y recreo».

En esta edición, Benito Remigio Noydens reproduce el texto de 1611 con la mayor parte de sus erratas e introduce material nuevo (las "Adiciones de Noydens", más numerosas en la segunda parte que en la primera ${ }^{22}$ ), sustituye los caracteres hebreos y griegos por los latinos, reagrupa algunas entradas, y elimina determinadas frases y referencias. El material de las Adiciones, unas 326 entradas, en su mayoría es de tipo enciclopédico, y sus informaciones en muchos casos están extraídas de la "Breue declaración de las sentencias y vocablos obscuros» que Alejo Venegas puso como apéndice de la Agonía del tránsito de muerte (1565).

3. La edición de Martín de Riquer (1943) ${ }^{23}$, como reza en el título, contiene el texto de la de Covarrubias (1611), más las adiciones de Noydens (1674), que se encuentran incluidas en su lugar correspondiente entre corchetes. En esta edición, que ha conocido varias reimpresiones facsimilares en distintas editoriales, con los preliminares del filólogo catalán o sin ellos, se reproduce el texto de la de Covarrubias (1611), en un tipo de letra paleográfica que imita la antigua, conservando "fielmente la redacción y la ortografía del original» ${ }^{24}$.

Martín de Riquer adapta el uso de las mayúsculas a las normas modernas, imprime en cursiva las palabras y frases latinas y extranjeras, regulariza la puntuación y acentuación, resuelve abreviaturas (salvo en citas de algunos libros bíblicos y latinos y en las indicaciones de lib. [libro], cap. [capitulo], etc.), sustituye la $v$ por la $u$ cuando se trata de la vocal y la $u$ por $v$ cuando es el

22. Las adiciones de Noydens, según Martín de Riquer, «aumentan de modo considerable en la segunda parte, precisamente cuando Covarrubias, por temor a no acabar con su empresa, decide abreviar» («El Tesoro de la Lengua Castellana o Española», Tesoro, 1943, p. XI).

23. Como se ha anotado anteriormente, en la portada se lee exactamente Sebastián de Covarrubias, Tesoro de la Lengua Castellana o Española según la impresión de 1611, con las adiciones de Benito Remigio Noydens publicadas en la de 1674. Edición preparada por Martín de Riquer, E. de la Real Academia de Buenas Letras y profesor de la Universidad de Barcelona, S. A. Horta, I. E., Barcelona, 1943.

24. Martín de Riquer, «El Tesoro...», Tesoro, 1943, p. XIII. 
sonido consonántico, añade entre corchetes las letras que faltan, indica letras que sobran y corrige erratas evidentes.

Por otro lado, respeta rigurosamente "el orden seguido por el texto en las dicciones ${ }^{25} \mathrm{e}$ imprime "como cabezas de artículo las palabras que así constan ${ }^{26}$, a pesar de lo cual, cuando figura como cabeza de artículo alguna voz derivada del artículo anterior y que no empieza por la misma letra, la incorpora al cuerpo del artículo anterior, y, viceversa, separa las entradas falsamente integradas en un mismo artículo y que en realidad constituyen dicciones autónomas.

4. En la edición de Felipe C. R. Maldonado, revisada por Manuel Camarero $(1994)^{27}$, en la que se incluyen las Adiciones de Noydens pero no el Suplemento, en el intento de adaptar la redacción de Covarrubias a una forma cercana a los diccionarios de nuestro tiempo, con la modernización se reordenan las entradas, pero se conservan también las grafías originales, estableciéndose un sistema de doble referencia mediante el cual de la forma antigua se establece una remisión a la modernizada ${ }^{28}$. Además, se enumeran las acepciones secundarias, que se imprimen en negrita, con lo que se facilita su localización.

Maldonado y Camarero corrigen erratas, incluso en las etimologías, respetando el texto de Covarrubias aunque la referencia sea errónea, porque, a su juicio, «buena parte del valor filológico y aun literario del Tesoro radica precisamente en las interpretaciones etimológicas ${ }^{29}$, destacando con asidua frecuencia tales indicaciones en versalitas; encierran entre diples letras o sílabas de palabras mal citadas con el fin de que el lector las interprete correctamente; $\mathrm{y}$ añaden dos índices, uno de refranes y proverbios, y otro de dichos y frases hechas.

Por otro lado, sin dejar de reconocer el mérito de esta edición, desaparecen algunos vocablos del Tesoro y aparecen otros no registrados en él (por ejemplo, alanzada se convierte en aranzada; arracife, en arrecife; visegodo y visogodo, en visigodo). Covarrubias trae ajenjios, asensios y ensensios, pero no ajenjos (aunque esta forma se cita en la entrada asensios); sin embargo, Maldonado y Camarero solamente recogen ajenjos (en vez de ajenjios), asensios (que sí figura en Covarrubias) y asenjos, que no se registra en todo el Tesoro (en lugar de ensensios $)^{30}$.

5. Covarrubias debió de comenzar el Suplemento -o Apéndice, denominación empleada por él- a la vez que el Tesoro, ya que, como advierte Dominique

25. Martín de Riquer, op. cit., p. XIV.

26. Martín de Riquer, ibid.

27. Sebastián de Covarrubias Orozco, Tesoro de la lengua castellana o española. Edición de Felipe C. R. Maldonado, revisada por Manuel Camarero, Madrid, Castalia, 1994.

28. Los editores explican que, «si la entrada o la referencia han sido modernizadas, aparecen entre corchetes, y a continuación siempre figura la forma original con las grafías que utilizara Covarrubias» ("Características de la presente edición», Tesoro, 1994, p. XVII).

29. Felipe C. R. Maldonado y Manuel Camarero, op. cit., p. XVIII.

30. A ello se ha de añadir que en el artículo de adefesios se mezcla un fragmento del de ademán; en el de águila falta una línea, y en los de amesnadores, día, idolo, latín y otros también falta parte del texto. 
Reyre, desde el principio "había comprendido que no iba a poder decirlo todo en su Tesoro por lo que guardó informaciones escribiéndolas en papeles sueltos a manera de fichas que pensaba utilizar para realizar un Apéndice» ${ }^{31}$.

En este repertorio fue incorporando voces nuevas o ampliando los artículos ya incluidos en la obra. Se trata en total de 2.179 artículos, la mayor parte de los cuales corresponden a nombres propios. Solo 429 pertenecen al léxico común, de los que 219 son entradas nuevas. Llama la atención sobre todo la importancia concedida a los arcaísmos y los tecnicismos.

El lexicógrafo toledano se preocupó de marcar la continuidad entre ambos componentes de su obra por signos tipográficos, señalando con una cruz los lemas que completaban las entradas del Tesoro y valiéndose también de la fórmula Añade escrita en la cabecera de los artículos, mientras que las entradas nuevas se indican con un asterisco.

El Suplemento conservado ${ }^{32}$ se inicia con Abacuq y termina en Moisés, sin que podamos saber si es ahí donde se quedó Covarrubias o se ha perdido el resto. Las dos primeras ediciones que se hicieron, la de Betty Bayliss (1959) ${ }^{33}$ y la de Juan Crespo Hidalgo $(1991)^{34}$, a pesar de su mérito intrínseco, no han tenido mucho impacto; la primera es parcial, y en la segunda -que es paleográfica- se incluyen listas de autoridades citadas y otros materiales.

Posteriormente, Georgina Dopico y Jacques Lezra han preparado otra edición $(2001)^{35}$, en la que respetan la redacción, la ortografía y el ritmo de Covarrubias; añaden acentos y diéresis de acuerdo con las normas actuales; regularizan mayúsculas conforme a las normas modernas; utilizan la $u$ para representar la vocal y la $v$ para la consonante; se sirven de la $i$ para la vocal y de $j$ para la consonante ${ }^{36}$; añaden traducciones del latín al castellano entre corchetes; imprimen en cursiva las palabras y frases en latín; incluyen las letras o palabras que ańaden entre diples; ponen el texto que suprimen (por superfluas o por enturbiar el sentido) entre paréntesis; y resuelven las abreviaturas (q. por que), excepto lib. (por libro); cap. (por capitulo); S., Sto., Sta. (por San, Santo, Santa); N. H. (por Nombre Hebreo); y v. (por verbo).

31. «Prólogo segundo. Las llaves del Tesoro de Covarrubias», en Sebastián de Covarrubias Horozco, Tesoro de la lengua castellana o española. Edición integral e ilustrada de Ignacio Arellano y Rafael Zafra, Universidad de Navarra; Madrid, Iberoamericana; Frankfurt am Main, Vervuert; Real Academia Española; Centro para la Edición de Clásicos Españoles, 2006, p. XLV. El Suplemento sin duda debió de formar parte del proyecto lexicográfico inicial del canónigo de la catedral de Cuenca a juzgar por sus propias palabras a propósito de algunas entradas de la letra A, como en Argos («Rey de los Arginos. Vide Apend.» [Tesoro, 1611, s. v.]) o en asbesto («Vide in appéndice» [Tesoro, 1611, s. v.]).

32. Manuscrito 6159 de la Biblioteca Nacional de Madrid, de 318 folios.

33. Betty Bayliss, Sebastián de Covarrubias. "Suplemento al Tesoro de la Lengua Castellana». A critical edition of selections from the original manuscript. Tesis de la University of Illinois, 1959.

34. Juan Crespo Hidalgo, Estudio del «Suplemento al Tesoro de la Lengua Española Castellana» de Sebastián de Covarrubias, Universidad de Málaga, 1991.

35. Sebastián de Covarrubias, Suplemento al Tesoro de la Lengua Española Castellana. Edición de Georgina Dopico y Jacques Lezra, Madrid, Ediciones Polifemo, 2001.

36. Salvo en los casos en que la vocal que se define comienza por $I$ consonante o Jvocal: Iudío. 
6. En su edición integral e ilustrada del Tesoro de Covarrubias $(2006)^{37}$, Ignacio Arellano y Rafael Zafra parten de la idea de que, para obtener una edición completa de la obra que pueda ser manejable, son necesarios dos requisitos, la modernización de las grafías sin relevancia fonética, la acentuación y la puntuación, y la reordenación del texto.

No obstante, mantienen las grafías de las citas de textos medievales, conservan las abreviaturas que no presentan dificultades y respetan los acentos de ciertas palabras que difieren de su versión moderna, adaptan las grafías de los textos latinos a su versión actual (aunque, como es natural, corrigen los errores ortográficos provocados por los cajistas o por el propio autor), y mantienen las citas en hebreo y en griego.

Arellano y Zafra intentan resolver todos los problemas que se les presentan, y, cuando es posible, adoptan la solución más próxima a la concepción original del autor. Incluir la forma modernizada entre corchetes y poner a continuación la antigua es un acierto. Las ilustraciones que acompañan a algunos vocablos o nombres propios constituyen una novedad y un enriquecimiento importante.

En el DVD que acompaña a la edición en papel, a la versión digital del texto íntegro se añade un facsímil fotográfico de la edición de 1611 y del manuscrito autógrafo del Suplemento. En esta versión, estructurada y marcada por medio de un software, "permite localizar de un modo sencillo desde palabras en otros idiomas, hasta refranes o emblemas, por poner algunos ejemploss ${ }^{38}$.

\section{Macroestructura del Tesoro}

La macroestructura del Tesoro, es decir, la organización del léxico recogido en él, consta de unas 11.000 entradas. Si a ellas se añaden las palabras que no cuentan con entrada propia y son definidas en el artículo correspondiente a otra, el elenco sería de 16.929. Incluyendo las adiciones del Suplemento y un registro interno de vocablos tenidos en cuenta en otros recuentos, la cifra se elevaría hasta unas $20.000^{39}$.

37. Sebastián de Covarrubias Horozco, Tesoro de la lengua castellana o española. Edición integral e ilustrada de Ignacio Arellano y Rafael Zafra, Universidad de Navarra; Madrid, Iberoamericana; Frankfurt am Main, Vervuert; Real Academia Española; Centro para la Edición de Clásicos Españoles, 2006.

38. Ignacio Arellano, «Prólogo primero. La edición integral e ilustrada del Tesoro de Covarrubias», Tesoro, 2006, p. XLII.

39. Como muestra del proceder de Covarrubias se puede citar el artículo de la voz alcohela, en el que anota que nos hallamos ante un «nombre arábigo diminutiuo qubiletum, negrillo, del verbo quehale, que vale ser negro. Por otro nombre se llama endiuia, de que los boticarios sacan agua; deuiose llamar assí por razón de su simiente, y úsanle los toledanos, y no haze mención deste nombre ningún autor de los que escriuen de plantis» (Tesoro, 1611, s. v.). John M. Hill (Index verborum de Covarrubias Orozco, "Tesoro de la lengua castellana o española, Madrid, 16111674", Bloomington, Indiana University Studies, 48, vol. VIII, 1921), teniendo en cuenta el elevado número de voces definidas en el interior de los artículos, optó por publicar un índice con todas las palabras contenidas en la obra, y Martín de Riquer incluyó al final de su edición 
En el orden alfabético con frecuencia se producen fallos e incongruencias (por ejemplo, aparece Alhamar y a continuación Alhama, andar y detrás andamio, altanería y antes alto, o cancillería y después cáncer), debidos a la inestabilidad gráfica propia de la época. Abundan las vacilaciones fonéticas (ignorante e inorante; azabache y açabache; avispa y abispa), y, aunque el autor se declara partidario del criterio fonetista en ortografía, no siempre es consecuente con este principio (anathema, hierarchia, hydropesía). Su mismo apellido aparece escrito como Cobarruuias (en la portada del Tesoro), Couarruuias (en el privilegio real del mismo) y Couarrubias (en los Emblemas morales).

La extensión de los artículos es desigual. Algunos ocupan un renglón (aterrar); otros abarcan tres páginas (asno); incluso los hay de ocho páginas (elefante); y los más numerosos son los que oscilan entre diez y veinte líneas (carrasca, deleite, ilustrar). En la nomenclatura se da un claro predominio de las entradas nominales, no solo de nombres comunes, sino también de nombres propios, topónimos o antropónimos, características propias de los diccionarios enciclopédicos ${ }^{40}$.

La concepción abarcadora del léxico de Covarrubias explica la presencia, junto a las voces no marcadas, de términos marcados por alguna característica sociolingüística (rústicos, poéticos, groseros), por su adscripción a ámbitos de especialidad (tecnicismos científicos, o relacionados con oficios, artes, técnicas o actividades diversas), por su restricción a áreas geográficas (sobre todo de Castilla la Vieja, reino de Toledo y Andalucía), o por designar variaciones cronológicas (arcaísmos procedentes de obras medievales, en especial las Siete Partidas y el Conde Lucanor, y vocablos antiguos castellanos, de los cuales unos no estaban desusados en el siglo XVII, mientras que de otros señala que estaban a punto de quedar anticuados) ${ }^{41}$.

otro índice con el fin de guiar al usuario en el «anárquico orden seguido por Covarrubias» («El Tesoro...", Tesoro, 1943, p. XV).

40. Si se presta atención solamente a las entradas, se podría sacar la conclusión de que en la obra existe un excesivo predominio de sustantivos; sin embargo, tomando en consideración también las subentradas, se comprueba que hay muchos verbos y sintagmas verbales, y, si el número de estos es inferior, se debe a que en el conjunto del léxico de la lengua son menos abundantes.

41. En diversos artículos del Tesoro se encuentran observaciones como «mascar, término vulgar, vale comer, dando dentelladas, y desmenuzando entre los dientes la vianda con alguna fuerça» (Tesoro, 1611, s. v.); "frondoso, término poético no vsado en la prosa, vale lleno de hojas» (Tesoro, $1611, s . v$.); «infusión, término de boticarios, de que vsan en el purificar los xaraues, como xaraue de nueue infusiones» (Tesoro, 1611, s. v.); «ventiquatro, en Seuilla, y en Córdoua, y en otros lugares del Andalucía, vale lo mesmo que en Castilla Regidor, por ser veynte y quatro regidores en número» (Tesoro,1611, s. v.); «sohez, palabra antigua, vale baxo, infame, de poco valor, y la hez de la República, y assí se dixo de sub y fax facis» (Tesoro, 1611, s. v.). Del mundo americano Covarrubias, según Juan M. Lope Blanch («Los indoamericanismos en el Tesoro de Covarrubias», Estudios de historia lingüistica hispánica, Madrid, Arco/Libros, 1990, pp. 153-174), consigna los vocablos acal, Araucana, cacique, caimán, canoa, coca, Cuzco, hamaca, huracán, inga, maiz, mechoacán, mexicano, México, mico, Motezuma, nopal, Perú, perulero, pita, Tenochtitlán, tiburón y tuna, en cuya relación faltan otros que ya se habían generalizado en la lengua, como bejuco, cacao y caribe. A esta relación Julio Calvo Pérez (Sebastián de Covarrubias o la fresca instilación 
La lematización de las unidades léxicas a menudo está estructurada en familias de la misma raíz, destacando como lema la considerada raíz de las demás, que no tienen artículo propio, lo que dificulta la consulta. Sin embargo, el autor no actúa de manera sistemática. En este sentido, con la familia amar, por ejemplo, ofrece tres entradas: en la primera amar incluye amor; la segunda, amores, detrás de la anterior, comprende (con ruptura del orden alfabético) amorio, amada, amigo, amiga, amador, amante, amigado, amigarse, adamar; y en la tercera, amor, cinco páginas después, repite amar, amores y amoríos, y añade amoricones.

Las palabras polisémicas unas veces cuentan con artículos distintos (araña 'animalejo de insectos...' y araña 'pez', arca 'caxa...' y arca 'de agua', autoridad 'estimación, eminencia' y autoridad 'razón escrita para fundar algún propósito'), y otras se encuentran incluidas todas en la misma entrada presentándose las restantes como acepciones suyas, como en el caso de flor 'yeruas...' + 'en el vino' + 'en la doncella...' + 'en los metales...'.

Las variantes gráficas o fonéticas de un mismo término, si bien es cierto que en algunos casos son resueltas mediante reenvíos de una forma a otra («alhózigo, vide alfócigo» ${ }^{42}$ y dentro de esta alhócigo sin reenvío), en otros aparecen juntas en la misma entrada (arquero y archero). A veces se producen errores gráficos: "almazén. Vide almacén» ${ }^{43}$ y este no existe, sino que hay otro artículo dedicado a almazén con $z$ mal colocado; en el artículo de apostema se indica «apostema. Vide postema» ${ }^{44}$, y en este, muy breve, se dice «nombre Griego ó $\pi$ ó $\left.\tau\right\rceil \eta \alpha$, suppuratio» ${ }^{45}$, figurando, en cambio, otro apostema unos renglones detrás del primero donde se dan más indicaciones ${ }^{46}$.

de las palabras, Diputación de Cuenca, 1991) añade las voces coco, cota, elefante, gigante, higuera de Indias, Honduras, India, lazo, marañón, pavo, perico, salgada y uracán, en las que se hace referencia al mundo americano. Lope Blanch piensa que nuestro lexicógrafo debió de manejar diversas crónicas americanas, fundamentalmente la Historia general de las Indias de Francisco López de Gómara, ya que, de lo contrario, no se podrían explicar ciertas coincidencias y la deuda contraída con algunos cronistas. Sin embargo, Covarrubias no acudió a ellas con la intención de hacer una búsqueda sistemática, puesto que hubiera incluido términos corrientes o topónimos conocidos, y es que «el mundo americano quedaba todavía un tanto distante y al margen de los intereses científicos de la mayor parte de los eruditos peninsulares». De todos modos, aduce la autoridad de José de Acosta al menos en tres artículos (bezoar, elefante y marfil), más otro del Suplemento (arfil).

42. Tesoro, 1611 , s. v.

43. Tesoro, 1611, s. v.

44. Tesoro, 1611, s. v.

45. Tesoro, 1611, s. v.

46. Las entradas del Suplemento, como se ha indicado anteriormente, responden en su mayor parte a los nombres propios («† Coria. (Añade). Esta ciudad es de los duques de Alva. El modo como vino en su poder podrás ver en la Crónica del rey don Enrique el quarto, y al padre Mariana, lib. 23, cap. 15" [Suplemento, 2001, s. v.]), a pesar de lo cual no dejan de constituir en cierto modo un grupo importante los arcaísmos ( «*agruador. Vocablo antiguo, quasi Augurator, el agorero» [Suplemento, 2001, s. v.]) y los términos marcados («*epopeia. Este nombre es Griego pero los escritores Españoles andan buscando títulos extraordinarios para los frontispicios de sus libros y ansí es necesario por este respeto declarar algunos. Digo pues que este término Epopeia 


\section{Microestructura del Tesoro}

1. La microestructura del Tesoro, o sea, la organización interna de cada artículo lexicográfico, se caracteriza por su heterogeneidad y por la mezcla de datos lingüísticos y enciclopédicos. Dentro de la información lingüística se pueden encontrar: a) la definición de la palabra-guía en sus diferentes acepciones; b) autoridades literarias que refrendan el uso de la palabra; c) equivalencias en latín; d) etimología propuesta (en ocasiones, después de la discusión de varias posibles); e) refranes u otras expresiones fraseológicas en que interviene la palabra; f) derivados léxicos y otras palabras de la misma familia ${ }^{47}$.

La información de tipo enciclopédico comprende: a) la descripción o explicación del referente; b) textos informativos o ilustrativos de carácter doctrinal o literario, antiguos o modernos, generalmente latinos; c) simbología; d) consideraciones y juicios morales; e) anécdotas y curiosidades, algunas de experiencia directa; f) bibliografía.

Lo más frecuente es que no se incluyan todos estos elementos en todos los artículos, sino solo algunos. La presencia o ausencia de cada uno de ellos es variable. Los más habituales son la definición y la etimología, aunque también pueden faltar. El orden en que se presentan no es fijo, si bien la definición y la etimología suelen ocupar el primer lugar. No resulta extraño que a una misma voz se le atribuyan etimologías diferentes en lugares distintos ${ }^{48}$.

La sintaxis de la exposición es espontánea, concorde con la llaneza con la que el autor tiende a expresarse en primera persona como si el diccionario fuese una charla familiar sobre una serie alfabética de temas. La impronta de la personalidad del compilador es querida y buscada. Quienes han tenido la oportunidad de consultar la obra con detenimiento han tenido la oportunidad de encontrarse por doquier con fragmentos que evidencian la humanidad y simpatía comunicativa del lexicógrafo toledano ${ }^{49}$.

vale tanto como carmen fictum [composición poética]. Dél usa Lope de Vega en su Gerusalem

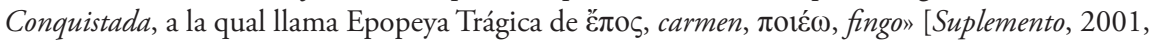
s. v.]).

47. Llama la atención la ausencia de indicación gramatical sobre las voces, salvo cuando se trata de las palabras gramaticales (con. «Lat. cum, preposición de hablatiuo» [Tesoro, 1611, s. v.]; quando «aduerbio de tiempo, Lat. quando» [Tesoro, 1611, s. v.]; que "partícula interrogatiua, o relatiua, se dixo de quis, vel qui» [Tesoro, 1611, s. v.]) (tampoco la ofrece el Vocabolario degli Accademici della Crusca [In Venezia, appresso Giouanni Alberti, 1612]).

48. Por ejemplo, acerca de calma, en el primer artículo que le dedica, comenta nuestro lexicógrafo que «puede ser nombre Griego, de $\kappa \alpha \tilde{\mu} \mu \alpha$, cauma, que vale calor, combustio, porque quando no corre aire en el verano, haze calor y se abrasan las gentes» (Tesoro, 1611, s. v. calma, fol. 175 v.); sin embargo, cinco páginas más adelante, en otro artículo del mismo vocablo, manifiesta: «inoré su etimología, aunque algunos dizen ser nombre Hebreo» (Tesoro, 1611, s. v. calma, fol. 178 r.).

49. Es lo que se advierte, entre otros muchos, en pasajes como «Alumbrados fueron ciertos Hereges que huuo en España muy perjudiciales, que trahían la piel de Ouejas, y eran Lobos rapaces» (Tesoro, 1611, s. v. alumbrar); "Sinifica también el lisonjero y adulador, que si lloráis llora, y si reís ríe, y si a medio día claro dezís vos que es de noche, os dirá que es assí, porque él 
2. La incorporación de autoridades en el Tesoro se debe al predominio de la información enciclopédica sobre la lingüística. Covarrubias incorpora al elenco unos quinientos autores, la mayor parte de los cuales son didácticos. Algunos de los literarios citados más asiduamente suelen actuar como testigos históricos, científicos, filosóficos o morales, pero no lingüísticos.

Por la lengua de los testimonios aportados, pueden establecerse tres grupos, el de lengua latina, el de lengua románica no española y el de lengua española. $\mathrm{Al}$ primero pertenecen las citas bíblicas extraídas de la Vulgata, los didácticos griegos -a través de traducciones latinas (y en el caso de Pedacio Dioscórides Anazarbeo, de una traducción española)-, los didácticos latinos, los Padres de la Iglesia y otros escritores cristianos, los tratadistas medievales, los humanistas y científicos del Renacimiento cuyo vehículo de expresión es la lengua latina, los poetas latinos y los pocos griegos citados.

El segundo comprende los escasos autores didácticos italianos del Renacimiento que escriben en su propia lengua, y los literatos italianos, franceses y portugueses que escribieron en sus respectivas lenguas vulgares, y el tercero se halla integrado por los textos didácticos y literarios, medievales o del Siglo de Oro, escritos y reproducidos en lengua española, incluidos los de la literatura popular.

Covarrubias muestra una gran admiración por los poetas latinos, especialmente Horacio, Virgilio y Marcial; los italianos Petrarca y Ariosto; el español Garcilaso; y, en menor medida, el portugués Camoens y el francés Ronsard. De los españoles, el único poeta contemporáneo de Garcilaso que menciona es Castillejo, y el único posterior, Ercilla (a quien llama Arcila). Por el contrario, no parece haber sido muy aficionado a los «que oy se vsan en la Corte» ${ }^{50}$. En cambio hay bastantes didácticos de todo ese período ${ }^{51}$.

vee las estrellas. Este tal merecía que se las hizieran ver realmente, con meterle en vn poço muy hondo" (Tesoro, 1611, s. v. camaleón); "Mahoma (que nunca huuiera nacido en el mundo) nació en Arabia, en el lugar llamado Zatrarip, que está cerca de Meca» (Tesoro, 1611, s. v. Mahoma). Manuel Alvar Ezquerra, basándose en Margherita Morreale ( Virgilio en el Tesoro de Sebastián de Covarrubias», Boletín de la Real Academia Española, LXVIII [1988], pp. 205-206), interpreta el estilo de la obra como "discursivo y falto de método, pues en ocasiones parece alargarse demasiado -especialmente en las cuatro primeras letras- y otras veces se trata de un resumen poco claro, y hasta incorrecto, de sus fuentes, por las prisas para rematar la tarea. A Covarrubias le faltaba un plan previo para redactar los artículos de su Tesoro, de ahí el anisomorfismo de las informaciones y del contenido, que son fácilmente detectables. De cualquier manera, contiene sobradamente los elementos necesarios para que, pese al desorden, podamos considerarlo como un diccionario, pues además del lema y las definiciones, aparecen referencias de carácter diastrático, diafásico y diacrónico -por más que no sean marcas en sentido estricto-, así como voces tildadas de nuevas, otras consideradas idiotismos que han de ser corregidos, refranes y proverbios, citas, y, especialmente, informaciones extralingüísticas» (art. cit., p. 73).

50. Tesoro, 1611, s. v. cuervo.

51. Entre ellos, Laguna, Arciniega, Jerónimo de Huerta, Monardes, Pineda, Poza, Acosta, Cieza de León, Diego Hurtado de Mendoza, Zurita, Ocampo, Morales, Garibay, Mariana, Argote de Molina, Sigüenza y Castillo de Bobadilla (Manuel Seco, Estudios de lexicografía española, 2. a ed., Madrid, Gredos, 2003, p. 199, n. 24). 
En las menciones de los autores latinos y griegos se percibe una notable diferencia, debida a que, mientras que las de los griegos se ofrecen sin texto, con texto traducido al latín o en simple resumen en español, las de los latinos casi siempre aparecen en estilo directo en su propio idioma, dada la familiaridad de Covarrubias con esta lengua, la misma que presupone en los lectores a los que dirige el libro, cosa que, si así no fuese, les recomienda que busquen quien les "declare» ${ }^{52}$ los pasajes que no entiendan o que «tengan paciencia»"

En la obra de Covarrubias también son representativas las citas de la poesía italiana. Él residió en Italia durante un corto período de tiempo. En diversos pasajes del libro demuestra un cierto conocimiento del toscano. Como muchos españoles de su época estaba familiarizado con la literatura italiana. Por todos estos motivos y en consonancia con las tendencias del momento es «un devoto de Petrarca " ${ }^{54}$, cuyos textos reproduce en su mismo idioma, salvo en dos ocasiones, basándose en las fuentes lexicográficas al uso. Los otros autores no debían de ser conocidos directamente por él o, al menos, no debían de gozar de una predilección tan intensa como Petrarca. Por supuesto, las literaturas francesa y portuguesa se hallan más distantes en el orden de sus preferencias ${ }^{55}$.

El número de citas literarias en espańol es inferior al de las latinas. Sin embargo, Covarrubias es consciente de la novedad que supone incorporarlas: "Con tanta autoridad y grauedad se puede alegar el diuino Garcilasso, en comprouación de la lengua Española, como Virgilio, y Homero, en la Latina y Griega. Y qualquier romance viejo, o cantarcillo comúnmente recebido; y assí yo no me desdeño quando viene a propósito de alegarlos, por comprouación de nuestra lengua» ${ }^{56}$. Nebrija ya había practicado esta costumbre en su Gramática, pero en lexicografía es la primera vez que se introduce este recurso, que cristalizará en el Diccionario de Autoridades.

Las obras, autores o textos españoles más citados son el Conde Lucanor, las Partidas, Juan de Mena (especialmente el Laberinto), las Coplas de Mingo

52. Tesoro, 1611, s. v. celoso.

53. Tesoro, 1611 , s. v. sátira. La diferencia apuntada se comprueba en el artículo de la voz almez, al recurrir a la autoridad del griego Homero («Escriue Homero, lib. 9, Odysea, que, auiendo comido los compañeros de Vlyses de la fruta del lotos, quedaron tan engolosinados della que a palos no los podía hazer boluer a las naues, determinados de desampararle, quedándose en aquella tierra por gozar de cosa tan gustosa» [Tesoro, 1611, s. v.]) y, más adelante, a la del latino Ovidio («Lotos, de que haze mención Ouidio, lib. 9: / Lotos in hanc Nimphe, fugiens obscena Priapi / Contulerat versos seruato nomine vultus» [Tesoro, 1611, s. v.]).

54. Manuel Seco, op. cit., p. 210.

55. En el artículo de la palabra costumbre aparecen citados el italiano Petrarca («Petrarca, soneto La gola, etc.: / La gola, el sonno et l'ostiose piume / Hanno del mondo ogni bertu sbandita / Ond'e dal corso suo quasi smarrita / Nostra natura vinta dal costume» [Tesoro, 1611, s. v.]) y el portugués Camoens («Dixo el famoso poeta portugués Camoys, en sus Lusiadas, hablando del Rey don Sebastián: / Acostumainos ya a ser inuocado, / imitando a Virgilio: Votis assuesce vocari» [Tesoro, 1611, s. v.]). El francés Ronsard, por su parte, comparece en el de burla para atestiguar su probable origen francés («Burla, puede ser vocablo francés, corrompido de bourde, que vale mentira jocosa. Ronsard, en sus poemas, tom. 3, fol. 55: / Gaieté / Assez vrayment on ne revère / Les diuinos bourdes d'Homère» [Tesoro, 1611, s. v.]).

56. Tesoro, 1611, s. v. cerca. 
Revulgo, La Celestina, la Soldadesca de Torres Naharro, Lope de Rueda y sobre todo, como se acaba de ver, Garcilaso, además de romances viejos y cantarcillos de la lírica popular ${ }^{57}$. La mayor parte de estas citas se insertan sin precisar el lugar de procedencia ni la obra. De Garcilaso solo en dos ocasiones se especifica que se trata de la Tercera Egloga ${ }^{58}$, aludiéndose otras dos veces, respectivamente, a «una égloga $»^{59}$ y a "aquel soneto» ${ }^{60}$.

3. En la composición del Tesoro Covarrubias utiliza sobre todo diccionarios y obras no propiamente lexicográficas provistas de índices alfabéticos. Para los términos latinos se sirve principalmente del Vocabulario español-latino (Diccionarium ex hispaniensi in latinum sermonen) (1495), y, a veces, del Diccionario latino-español (Lexicon hoc est dictionarium ex sermone latino in hispaniensem) (1492), de Antonio de Nebrija, así como del Dictionarium linguae latinae (1502), de Ambrogio Calepino; $\mathrm{y}$, en menor escala, del Lexicon de partibus aedium (1535), de Francesco Mario Grapaldi; el Lexicon ecclesiasticum (1566), de Diego Jiménez Arias; y las Elegantiarum linguae latinae (1538), de Lorenzo Valla ${ }^{61}$.

Por lo que respecta al hebreo, alude explícitamente a Fray Pedro de Palencia, famoso profesor de hebreo de la Universidad de Salamanca ${ }^{62}$; la Perfectissima Hebraea grammatica (1557), de Juan Isach; el De varia in hebraicis libris lectione (1572), de Benito Arias Montano; el Thesauri hebraicae linguae (1572), del dominico Sante Pagnino (revisado por Arias Montano); y el Globus canonum et arcanorum linguae sanctae (1586), del portugués Fray Luiz de Sao Francisco ${ }^{63}$.

57. La presencia de la canción popular como autoridad en el diccionario, según Manuel Seco, "es uno de los rasgos más personales de Covarrubias en la historia de nuestra lexicografía. Juan de Valdés, en su aprecio de los refranes como ejemplos de la "puridad de la lengua castellana" (15351536: 38), era un precedente valioso dentro de la lingüística. Pero Covarrubias va más allá: no solo registra y explica multitud de refranes, sino que valora la poesía tradicional, para el estudio del léxico, a la misma altura que las obras de los poetas más celebrados» (op. cit., pp. 217-218).

58. Tesoro, 1611, s. v. cerca y s. v. calabozo.

59. Tesoro, 1611, s. v. hurto.

60. Tesoro, 1611, s. v. Abydo. En el artículo de aplacar, por ejemplo, Garcilaso es citado de esta manera: «El ilustre cauallero y famoso poeta Garcilasso de la Vega: / Si de mi baxa lira / Tanto pudiesse el son, que en un momento / Aplacasse la ira / Del animoso viento / Y la furia del mar y el mouimiento» (Tesoro, 1611, s. v.).

61. Nebrija es citado en el Tesoro en 243 artículos. La mención del origen del equivalente latino atribuido a él constituye un garante de la definición espańola o del sinónimo presentado por Covarrubias. De Calepino, tan utilizado como Nebrija aunque menos citado, Covarrubias toma prestada la definición, citada en latín o traducida al español, aunque a veces la diferencia de sentido le obliga a rectificar o adaptar la información. Obsérvese cómo son citadas las fuentes latinas en los artículos de oropéndola ("Aue conocida, dicha assí porque tiene las plumas doradas, o el pecho amarillo; Lat. secundum Nebrissensem galbula icterus» [Tesoro, 1611, s. v.]), majuelo («la viña nueuamente plantada. Díxose del nombre Latino malleolus, que vale postura de sarmiento. Calepinus verbo malleolus, nouus palmes vitis innatus prioris anni flagello" [Tesoro, 1611, s. v.]) o Pascua («Podrás ver al padre Diego Ximénez Arias en su Vocabulario Ecclesiástico, que lo trata extensamente» [Tesoro, 1611, s. v.]).

62. Elvira Pérez Ferreiro, Glosas rabinicas y sagrada escritura. Tratado de Pedro de Palencia, O. P., sobre la utilidad de las glosas rabinicas. Transcripción y estudio, Salamanca, San Esteban, 2004.

63. El hebreo, lengua de la que Covarrubias había adquirido unos conocimientos suficientes 
En cuanto al griego, cita el Lexicon graecolatinum novum (1589), de Iohannes Scapula; el Lexicon graecum et institutiones linguae graecae ad sacri apparatus instructionem (1572), de Benito Arias Montano; el Thesauros thes hellenichés glosses = Thesaurus Graecae linguae (1572), de Henri Estienne; el Lexicon graecolatinum seu thesaurus linguae graecae (1554), de Guillaume Budé; la traducción del libro de Pedacio Dioscórides Anazarbeo Acerca de la materia medicinal y de los venenos mortiferos (1555), realizada por Andrés de Laguna; el Liber de differentia linguarum vulgarium et Gallici sermonis varietate (1533), de Charles de Bovelles; la Orthographía y pronunciación castellana (1582), de Juan López de Velasco; la «Breue declaración de las sentencias y vocablos obscuros», que figura como apéndice de la Agonía del tránsito de muerte (1565), de Alejo Venegas; el Theatrum orbis terrarum (1570) y la Synonimia geographica (1578), de Abraham Ortelius $^{64}$.

En lo concerniente a los términos del árabe, lengua que no conoce, tiene en cuenta la referencia directa de Diego de Urrea ${ }^{65}$; el Compendio de algunos vocablos arábigos introduzidos en lengua castellana (1585), de Francisco López Tamarid; la Recopilación de algunos nombres arábigos (1593), de Diego de Guadix; y la Orthographía y pronunciación castellana (1582), de Juan López de Velasco (que le sirve también, como se ha podido comprobar, para los vocablos del griego ${ }^{66}$.

en la Universidad de Salamanca, ocupa dentro de su concepción lingüística un lugar importante, ya que piensa que el árabe es una corrupción de esta lengua, por lo que averiguar el origen hebreo de cualquier palabra es dar a conocer su verdadero origen. La familiaridad del lexicógrafo toledano con esta lengua puede comprobarse al mencionar las fuentes en los artículos de carámbano ("yo entiendo ser Hebreo, o del verbo carar, frigescere, o del nombre qerahh, glacies, gelu, crystallus, como lo siente el padre fray Pedro de Palencia» [Tesoro, 1611, s. v.]), cantarero («Y aunque hemos dicho ser nombre Griego, trae su origen de la lengua Hebrea, del nombre cantar. Arias Montano: Canthari nomen refert, vas erat portatu facile, vbi plenum essets [Tesoro, 1611, s. v.]) o derramar («Vide Globum lingae sanctae, lib. 2, cap. I. Esaias, cap. 10: Et excidet arbores perplexas siluae ferro" [Tesoro, 1611, s. v.]).

64. La soltura con que el canónigo de la catedral de Cuenca maneja las fuentes del griego queda patente en los artículos de esparto («Scapula, en su Lexicon, da su origen del verbo Griego

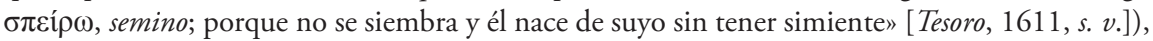
pandectas ("Es nombre Griego, $\pi \alpha v \delta \varepsilon ́ \kappa \tau \alpha 1$, volumina sunt (inquit Budaeus) nibil non continentia et ex quibus possis, quod velis velut e conucopia depromere. Vnde Pandectae Legum, qui omne ius complectuntur, a $\pi \tilde{\alpha} v$, omne, et $\delta \varepsilon ́ \chi 0 \mu \alpha 1$, capio» [Tesoro, 1611, s. v.]) o esmeril («Díxose del verbo $\sigma \mu \alpha ́ \omega$, abstergo, detergo, purgo. De esmeril haze vn capítulo Dioscórides, lib. 5, cap. 123, y allí verás a Laguna» [Tesoro, 1611, s. v.]).

65. Diego de Urrea es presentado por Fernando Rodríguez Mediano y Mercedes García-Arenal como «uno de los traductores e intérpretes más importantes de finales del s. XVI y principios del XVII en España. Sus actividades como catedrático en Alcalá de Henares, traductor de los Plomos del Sacromonte, catalogador de los manuscritos árabes de El Escorial, negociador intermediario y espía en asuntos marroquíes, hacen de él una figura paradigmática de lo que significó en su época el conocimiento y la utilización del árabe, como instrumento para cuestiones de importancia política y estratégica inmediata y también en su dimensión humanística y académica» («Diego de Urrea y algún traductor más: en torno a las versiones de los "plomos"”, Al-qantara. Revista de estudios árabes, 23, 2 [2002], p. 499).

66. El recurso a las fuentes para el árabe se refleja en los artículos de alambique («Vrrea dize 
La principal fuente del léxico italiano utilizada por Covarrubias, quien, como consecuencia de su estancia en Roma, tiene un conocimiento directo de esta lengua, fue la Fabrica del mondo (1557), de Francesco Alunno da Ferrara ${ }^{67}$; y, en menor medida, el Vocabulario de las dos lenguas toscana y castellana (1570), de Cristóbal de Las Casas, y el Dittionario volgare et latino (1561), de Filippo Venuti da Cortona ${ }^{68}$.

La terminología francesa está representada por el Dictionariolum LatinoGraeco-Gallicum (1577), de Horatius Tuscanella; el Dictionnaire françois-latin (1549), de Robert Estienne; el Dictionnaire François latin (1564), de Jean Jacques Thierry; el Dictionnaire françois-latin (1573), de Jean Nicot y Jacques Dupuys; y el Thresor de la langue françoyse (1606), de Jean Nicot. A este material se ha de añadir la ya citada traducción del libro de Pedacio Dioscórides Anazarbeo Acerca de la materia medicinal y de los venenos mortíferos (1555), realizada por Andrés de Laguna; y el Vocabulario del humanista (1569), de Juan Lorenzo Palmireno ${ }^{69}$.

Los vocablos del alemán tienen como fuente predominante los Origines Antwerpianae (1569), los Hermathena y los Hieroglyphica (en Opera, [1580]), de Johannes Goropius Becanus; a la que se suman otras, como las Etimologías españolas (1580), atribuidas al Brocense (a las que nos hemos referido anteriormente); e incluso el Liber de differentia linguarum vulgarium et Gallici sermonis varietate (1533), de Charles Bovelles (empleado asimismo para los términos del griego); y la Historia de gentium Septentrionalium uariis conditionibus (1567), de Olaus Magnus ${ }^{70}$.

ser nombre Arábigo, embicum, de verbo embeca, que sinifica salirse la sustancia distilándose, como distila la vid cortada quando la podan» [Tesoro, 1611, s. v.]), diques ("Tamarid: Dique, es angostura, defensa, o vallado; es vocablo Teutónico, y Arábigo» [Tesoro, 1611, s. v.]) u hogaza ("Juan López de Velasco dize que hogaza es nombre Arábigo, corrompido de hobayza, de hobiz, que vale pan» [Tesoro, 1611, s. v.]).

67. La obra de Francesco Alunno da Ferrara viene a ser para el italiano el equivalente de la de Ambrogio Calepino para el latín.

68. Como muestra de las fuentes del italiano se pueden citar las que se encuentran en los artículos de estocada («Francisco Alunno, en la Fábrica del mundo: Stecchi sono legni piccioli et pungenti» [Tesoro, 1611, s. v.]), badajo ("Está este vocablo corrompido del nombre Italiano Bataglio, que Casas buelue en Castellano badajo» [Tesoro, 1611, s. v.]) o bizarría («M. Filipo Venuti de Cortona, en su diccionario Italiano, y Latino, dize assí: Bizarro val duro di testa, fantastico, cerebrosus» [Tesoro, 1611, s. v.]).

69. De acuerdo con lo apuntado, contienen fuentes del léxico francés artículos como blasón ("Horatio Tuscanela, en su diccionario Latino, Graeco, Gállico, dize assí: Blason significe aucunefoes l'escu d'vn cheualier, peint et armoirie des armoiries et deuise du chaualien, [Tesoro, 1611, s. v.]), açogue ( $(\mathrm{El}$ Doctor Laguna haze vn galano discurso del azogue, o argento viuo, sobre Dioscórides, lib. 5, c. 69" [Tesoro, 1611, s. v.]) o esmeralda («Palmireno, en su Vocabulario de metales, dize grandes cosas de la esmeralda, vltra de las que sacó de Plinio, y cuenta cómo los Ginoueses llevaron de la presa de Almería, quando la ganó de los moros el Rey don Alfonso de Castilla, llamado Emperador, un plato de esmeralda, joya singular y única en el mundo, la qual antiguamente los Castellanos llamaron el santo Grial» [Tesoro, 1611, s. v.]).

70. Las referencias a las fuentes de los términos alemanes se registran, por ejemplo, en los artículos de godo ("Goropio, en sus Hieroglyficos, lib. 10, verbo Gimel., fol. 141, dize assí: Pater enim Got est, qua voce simpliciter Deum vocamus; si de aquí deriuamos el nombre de Godos, 
Por lo que se refiere a las fuentes etimológicas españolas, tiene presente la "Breue declaración de las sentencias y vocablos obscuros», al final de la Agonía del tránsito de muerte (1565), de Alejo Venegas; las Etimologías españolas (1580), atribuidas al Brocense (que, como se acaba de ver, son utilizadas también para las voces del alemán); y la Hydrografía (1585) y el De la antigua lengua, poblaciones y comarcas de las Españas (1587), de Andrés de Poza. En los adagios, proverbios y refranes, términos que Covarrubias, como la mayor parte de los lexicógrafos y tratadistas de su época, no diferencia, se basa en los Adagiorum chiliades (1536), de Erasmo, y los Refranes o proverbios en romance (1578), de Hernán Núñez, el Comendador Griego ${ }^{71}$.

\section{INFLUENCIA DEL TESORO}

La justa estimación de la tarea de Covarrubias tardó en producirse a pesar de servir de fuente para repertorios bilingües posteriores, como el Thresor de deux langues françoise et spagnole (1616), de César Oudin; el Ductor in linguas (1617), de John Minsheu; el Diccionario nuevo de las lenguas española y francesa (1705), de Francisco Sobrino; el A new Spanish and English Dictionary (1706), de John Stevens; el Vocabolario italiano e spagnolo (1620), de Lorenzo Franciosini; el Diccionario castellano y portuguez (1721), de Raphael Bluteau; o el Diccionario muy copioso de la lengua española y alemana (1670), de Nicolas Mez von Braindenbach ${ }^{72}$.

La auténtica valoración de la obra de Covarrubias se produce con los fundadores de la Real Academia Espańola. El Tesoro, como advierte Fernando Lázaro Carreter, es «un libro que la Academia estudió, usó ampliamente y

hemos de decir que son estimados como Éroas y hombres buenos, porque según el mesmo autor, en su Hermatena, lib. 6, fol. 125, dize que Goet vale bonum, a Got, qua voce Deum vocamus, quia bonum a Deo descendit et ad Deum deducit» [Tesoro, 1611, s. v.]), Flandes ("Carolo Bouilio dize ser nombre corrompido de forest lant, silue, patria; lant, en lengua Alemana, vale patria» [Tesoro, 1611, s. v.]) o ganado («En las partes septentrionales, con las pieles de las martas cebellinas y de otros animales contratan, como con el dinero, según lo refiere Olao Magno en su Historia» [Tesoro, 1611, s. v.]). Por otro lado, de los diccionarios multilingües en el Tesoro se menciona el Nomenclator omnium rerum (1567), de Hadrianus Junius, citado, por ejemplo, en el artículo de espadaña ("Al Bohordo llama Adriano Iunior, en su Nomenclator, septrum morionis» [Tesoro, $1611, s . v]$.$) .$

71. Las fuentes etimológicas españolas se encuentran incluidas en voces del tipo de cosa («Alexo Vanegas, al fin de su libro llamado Agonía de la muerte, dize que cosa se dixo de causa» [Tesoro, 1611, s. v.]), moscatel («El Brocense: Moscateles, appianae vuae, quas muscae appetunt» [Tesoro, 1611, s. v.]) o Barahona («el Comendador Griego, en sus refranes, trae vno que dize assí: En el campo de Barahora, más vale mala capa que buena hazcona» [Tesoro, 1611, s. v.]).

72. El Tesoro se erigió igualmente en fuente de informaciones para diccionarios monolingües de otros idiomas, como el Dictionnaire françois (1680), de César-Pierre Richelet, o el Dictionnaire universel (1690), de Antoine Furetière, así como para las gramáticas que incorporaban elementos léxicos del español, entre las que cabe destacar los Origines de la langue française (1650), de Gilles Ménage, cuyo trato hacia nuestro lexicógrafo fue bastante despectivo. 
veneró» ${ }^{73}$. Los miembros de la corporación destacan en el autor el mérito de haber sido el compilador del único repertorio léxico existente en español con anterioridad a 1713 .

Los académicos reconocen la importancia de la obra para poder llevar a cabo eficazmente la empresa en la que se hallan comprometidos. Se muestran comprensivos con el hecho de que, dada la amplitud del caudal léxico contenido en ella, no se encuentren incluidas todas las palabras de la lengua, y ponen de relieve el mérito, no de sus etimologías, que desestiman discretamente, sino de su aportación lexicográfica pura. En este sentido, ya en el prólogo del Diccionario de Autoridades se afirma:

Es evidente que a este autor se le debe la gloria de haver dado principio a obra tan grande que ha servido a la Academia de clara luz en la confusa obscuridad de empresa tan insigne; pero a este sabio escritor no le fue fácil agotar el dilatado océano de la lengua española, por la multitud de sus voces; y assí, quedó aquella obra, aunque loable, defectuosa, por faltarle crecido número de palabras; pero la Real Academia, venerando el noble pensamiento de Covarrubias y siguiéndole en las voces en que halló proporción y verosimilitud, ha formado el Diccionario sujetándose a aquellos principios y continuando después debaxo de las reglas que le han parecido adequadas y convenientes, sin detenerse con demasiada reflexión en el origen y derivación de las voces; porque, además de ser trabajo de poco fruto, sería penoso y desagradable a los lectores, que regularmente buscan la propriedad del significado ${ }^{74}$.

En las páginas del primer diccionario académico figura el Tesoro de Covarrubias como la obra lexicográfica más aprovechada y citada, especialmente en la elección de los lemas, ortografía y variantes formales, en las definiciones, descripciones e informaciones de índole enciclopédica y, por supuesto, en el terreno de la etimología, aceptando sus soluciones en numerosas ocasiones o discutiéndolas en otras.

Sin embargo, como autoridad, en la sesión académica del 10 de febrero de 1724 se apuntó la conveniencia de reducir el número de citas de la obra de Covarrubias, salvo en aquellos casos en los que una voz común no se encontrase documentada en ningún otro autor o, tratándose de un vocablo raro, aunque se dispusiese de autoridad, para confirmar su existencia, y se aprobó por mayoría de votos tras una larga discusión:

Diose cuenta por el Sr. D. Lorenzo de Cardona que en las concurrencias que â tenido con el Sr. D. Adrián de Conink para el examen de lo que se le va entregando por los Sres. que forman el Diccionario se havía advertido venir citadas muchas autoridades del Thesoro de la Lengua Castellana de Covarrubias, copiando sus palabras para la calificación de voces que se hallan mezcladas en la explicación de otra, con que no se le cita como Diccionario sino como Autor particular, y propuso algunos reparos que se le ofrecían sobre el modo de valerse de dicha obra, que solo les parece deve servir

73. «El primer diccionario de la Academia», Estudios de lingüística, Barcelona, Crítica, 1981, p. 93.

74. Diccionario de Autoridades (6 vols., 1726-1739). Edición facsímil, Madrid, Gredos, 2002, pp. I-II. 
para autorizar las voces que trahe en ella explicadas como de Diccionario. Habiéndose discurrido largamente sobre ello, y representándose por los Sres. D. Manuel de Villegas y D. Hernando de Bustillos que las autoridades de Covarrubias en qualquier modo que se usase de estas, devían ser mui apreciables, se pasó â votar, y quedó resuelto por maior parte de votos se puedan citar siempre las voces que trahe explicadas como Diccionario, pero que se excuse poner las demás autoridades siempre que aya alguna de otro autor, y que no hallándola se ponga la suya aun en las voces comunes, y que si la voz fuese rara aunque aya otra autoridad se pueda ańadir la de Covarrubias para corroborarla más ${ }^{75}$.

\section{Conclusiones}

El Tesoro de la lengua castellana o española, compuesto por Covarrabias en su mayor parte entre 1606 y 1610 con la intención de investigar las etimologías de nuestra lengua siguiendo el modelo de las Etymologiae de San Isidoro, que hiciera lo propio con el latín, una vez concluido y publicado (1611) se erige en el primer diccionario monolingüe de un idioma vulgar, no solo de España, sino también de Europa, aunque en algunos aspectos se asemeja más bien a una enciclopedia moderna.

Aunque el éxito editorial de la obra, dirigida a un público culto, no debió de ser muy grande en su tiempo, la han reeditado, tratando con mayor o menor acierto el texto con vistas a su perfeccionamiento y acercamiento al lector, investigadores de relieve como Benito Remigio Noydens (1674), Martín de Riquer (1943), Felipe C. R. Maldonado (1994), e Ignacio Arellano y Rafael Zafra (2006). Algo similar ha ocurrido con el Suplemento, del que, entre otras, disponemos de la meritoria edición de 2001 preparada por Georgina Dopico y Jacques Lezra.

El lexicógrafo toledano, cuyo punto fuerte no son precisamente las etimologías al estar condicionadas con frecuencia por su prejuicio hebraísta, logra reunir con una concepción totalizadora de la lengua un copioso caudal de voces, expresiones y refranes, revelándose, más que como un riguroso estructurador del léxico, como un apasionado observador del habla viva y de los diferentes registros y niveles al transmitir sus observaciones acerca de personas o cosas de la época o informar sobre datos eruditos.

El criterio de autoridad, de acuerdo con la actitud de los humanistas vulgares de la época, es relativamente amplio, por lo que, al lado de los poetas y autores cultos, extranjeros o espańoles, figuran otras creaciones autóctonas de carácter popular y tradicional, utilizándose como fuentes un amplio número de diccionarios u obras no propiamente lexicográficas provistas de índices alfabéticos del latín, hebreo, griego, árabe, italiano, francés, alemán y español. 
El Tesoro ejerció una clara influencia en la lexicografía plurilingüe del español y otro idioma del siglo XVII, pero el verdadero reconocimiento a la labor de Covarrubias no llegará hasta que, una vez fundada, la Real Academia Española lo tome como referente de primer orden para la redacción del Diccionario de Autoridades. Si bien es cierto que el prestigio del diccionario académico oscureció la estela del Tesoro, este salió del olvido y recuperó su lugar en la historia de la lexicografía española y universal a mediados del siglo XX gracias a la cuidadísima edición de Martín de Riquer. 